\title{
Internet Plagiarism among Form Four Chemistry Students of a Selected Malaysian Secondary School: Exploring Its Prevalence, Correlates and Gender Differences
}

\author{
Rajiah Hassan \\ SMK Sungai Pusu, Gombak \\ Kuala Lumpur \\ rajiah75@yahoo.com
}

\author{
Tunku Badariah Tunku Ahmad \\ Kulliyyah of Education, \\ International Islamic University Malaysia \\ Kuala Lumpur \\ tbadariah@iium.edu.my
}

\begin{abstract}
This case study was conducted to investigate the extent and prevalence of Internet plagiarism among a group of upper secondary students taking Chemistry as an elective subject at a selected public school in Kuala Lumpur. Eighty-seven (N=87) Form Four Chemistry students were required to write a two-page essay on acid rain as part of the School-Based Assessment exercise. The essays were examined in a quantified document analysis to record the occurrences and prevalence of plagiarism from Internet sources. Researcher-coded scores and Turnitin similarity indexes were used as the measures of Internet plagiarism. The results show that Internet plagiarism in this student body was widespread (99\%) as almost everyone plagiarized, except one female student. The amount of information copied was extremely high at an average of $90 \%$ for Turnitin similarity indexes and $91.3 \%$ for researcher-coded scores. Gender wise, both boys and girls plagiarized at about the same extent, and the slight difference between them did not account for any statistical significance. Most were involved in high-scale plagiarism, and appeared to have lifted their essays completely off the Internet. However, the study could not completely ascertain whether students' lack of ability in English and Chemistry was the actual reason for their plagiarism act as measures of the two subjects turned out to be weak correlates of plagiarism. Based on the findings, the study recommends that students be explicitly taught the proper skills of writing and educated about the nature and implications of Internet plagiarism.
\end{abstract}

Keywords: Internet plagiarism, correlates of Internet plagiarism, gender differences in plagiarism, English proficiency, Chemistry achievement, quantified document analysis, Turnitin similarity indexes

\section{INTRODUCTION}

Plagiarism, as we know it today, has been around for at least 300 hundred years (Howards, 2007), and is currently a huge problem in educational settings (Breen \& Maassen, 2005). According to Olcott (2001), it is centuries old. Plagiarism had actually existed among intellectuals and writers as early as in the ancient Greek world, dated from the 5th century BC to the 5th century AD. A large amount of identical wordings and sentences were detected in several ancient texts produced within that time period. In fact, popular and well-known scholars and writers such as Homer, Plato, Socrates and Aristotle were said to have borrowed Malaysian a lot of wordings and text from earlier works without acknowledgement (Hansen, 2003). At that time, the texts were normally taken from biblical sources (Olcott, 2001). This extensive 
borrowing phenomenon was believed to have been caused by "mimesis," which is the Greek concept of imitation in the name of spreading the message of God.

However, in the 16th century, a reformation in Western Europe changed public attitude towards plagiarism. People started to understand and value the importance of the concepts of originality and individual thought. In 1440, the invention of printing press in the Roman Empire by a German inventor, Johannes Gutenberg, helped to spread this new awareness of plagiarism and augmented public respect towards copyright and originality. When the government of England implemented its first copyright law in 1710, the move further enhanced public understanding of original thought and plagiarism. Some decades later in 1790, the United States followed suit by implementing their first copyright law in order to preserve the originality of ideas (Hansen, 2003).

In the current age, plagiarism has become widespread as the Internet permeates every sphere of education and information sharing activities. With the proliferation of highly userfriendly word processing software, plagiarism is turning epidemic (Batane, 2010; Price \& Price, 2005). Modern societies are now living in a highly digitalized era where knowledge is readily available everywhere on the Internet. This information superhighway exposes students to a multitude of resources for learning. Not surprisingly, the digital revolution has also brought with it tremendous opportunities for plagiarism (Howard, 2007), and has in fact made it even easier for students to plagiarize.

Internet plagiarism refers to the use of written work, photographs, or graphics from any online website that does not give credit to the author or founder of the original content (Batane, 2010; Scanlon \& Neumann, 2002; Sisti, 2007). In most cases where written work is concerned, Internet plagiarism involves the act of copying and pasting information verbatim from an Internet source, without rephrasing or citing the original creator (Scanlon \& Neumann, 2002). Few students know that there are copyright laws that protect online content--that online content has the same right as printed materials. Many think that copying and pasting digital content without acknowledging the original source is not equivalent to stealing and is, therefore, not morally wrong (Wood, 2004).

Living and working in a developing nation, Malaysian educators face the same problems as their counterparts in other countries in regard to plagiarism. Students in Malaysia are exposed to a huge repertoire of information and learning resources made available by the Internet (Wee, 1999; Chan, 2002). While the access opens up a huge door to knowledge, it can also easily lead students into the realm of bad moral values and academic crimes in the likes of cheating and plagiarizing. Previous research on plagiarism (e.g., Yusof \& Masrom, 2011; Arieff, Ahmad, Azmi, Mohd Nasir, \& Norazmallail, 2012) found that Malaysian university students were unclear of what plagiarism is. If that is the case with tertiary students, less can be expected of school students. This lack of understanding about what constitutes plagiarism will likely cause students to commit Internet plagiarism.

\section{LITERATURE REVIEW}

This section synthesizes the empirical evidence pertaining to the study's main research foci: prevalence of internet plagiarism, gender differences and influence of students' English language competency and subject-specific ability. 


\section{Prevalence of Internet Plagiarism among Students}

Studies on Internet plagiarism have been ongoing since the mid-1990s when the Internet became widely adopted and public awareness of cyber ethics rose in importance (Austin \& Brown, 1999; Denning, 1995; Klausman, 1999). For the past two decades, Internet plagiarism has created major problems in learning institutions (Scanlon \& Neumann, 2002; Selwyn, 2008) and the numbers that plagiarize digital content are growing by the thousands ( $\mathrm{Ma}, \mathrm{Lu}$, Turner, \& Wan, 2007). Among college and middle-school students, several factors contribute to this phenomenon, for example peer culture, the nature of websites, pressure of achievement, too easy and far reaching access, language problems and students' limited understanding of the nature of plagiarism (Lahur, 2004; Selwyn, 2008; Ma et al., 2007).

An alarmingly high prevalence of Internet plagiarism among middle school and high school students in the United States was documented by Ma et al. (2007) and Sisti (2007), respectively. The former study revealed that middle school teenagers are not conscious of their Internet experiences related to plagiarism, while Sisti (2007) found that $98 \%$ of high school students used the Internet for homework and research papers, and 35\% of them reported directly copying and pasting Internet materials into assignments without citations. Selwyn (2008) did a study that revealed $61.9 \%$ of students engaged in some form of online plagiarism.

This shows that the act of plagiarism, especially that involving Internet materials, is epidemic even among middle and high school student populations. In Lidija, Vedran, Tamara, Josip, and Mladen (2005), only a small percentage of students (9\%) were free from the practice. About 34\% plagiarized in small amounts, while 57\% took whole works verbatim from the Internet without paraphrasing or proper citations. Most students do not equate plagiarism to cheating, and see nothing wrong in taking information verbatim from the Internet (Sisti, 2007). Quite interestingly, high school students are reported to be more tolerant towards cheating than college students (Jensen, Arnett, Feldman, \& Cauffman 2002). They think that cheating and plagiarizing off Internet material are acceptable ways of doing homework. This phenomenon brings much dilemma to teachers as it is quite hard to curb the activities of students that engage in Internet plagiarism (Price \& Price, 2005).

\section{Gender Differences in Internet Plagiarism}

Research on gender differences in Internet plagiarism is quite abundant, but with inconclusive results. The main questions remain, "Do boys plagiarize more than girls? Is there a gender difference in the misconduct?" The assumption is that male students and those who are less able academically have a greater tendency to commit this act of cheating. But this assumption has been empirically challenged by some inconclusive results. Lidija et al. (2005) found no statistically significant difference between male and female medical students; they appeared to plagiarize the same amount of Internet information. Walker (2010) in a New Zealand study shared the same finding--the prevalence of cheating among males was about the same as that among females. On the contrary, Selwyn (2008) and Marshall and Garry (2005) found male students to plagiarize more than females, an observation consistent with Rosman et al. (2012) who studied Malaysian university students' perceptions toward various plagiarism acts. Their conclusion was the frequency of engaging in plagiarism was higher among boys $(\mathrm{M}=2.32)$ than girls $(\mathrm{M}=2.06)$, and the difference was statistically significant. Researchers have attributed this greater tendency to cheat among male students to two factors: (i) they are more ICT- and Internet-literate than female students (Selwyn, 2008); (ii) they are more frequent users 
of the Internet and download more digital stuff than female students (Marshall \& Garry, 2005). These factors might have been the cause of higher rates of cheating and plagiarism among male students in the said studies.

It could be summarized that in some studies, male students were shown to have a greater tendency to engage in dishonest practices in finishing assignments (Williams, Nathanson, \& Paulhus, 2010), and use more plagiarized content than female students (Marshall \& Garry, 2005; Selwyn, 2008; Jereb, Perc, Lämmlein, Jerebic, Urh, Podbregar \& Sprajc, 2018). In others, male and female students were shown to plagiarize at the same extent and level with no statistically significant differences observed in their Internet plagiarism practices (Lidija et al., 2005; Walker, 2010). However, the researchers were unable to locate any study that shows female students plagiarized more compared to male students.

\section{English Proficiency and Internet Plagiarism}

Is English proficiency the reason why some students cheat in their assignments? Researchers have acknowledged language problems as one of the factors that explain cheating, while some studies have made a direct link between English language proficiency and Internet plagiarism. Lahur (2004), who studied Asian learners enrolled in a foundation program at an Australian university in Malaysia, found that students with a low English proficiency had a greater tendency to plagiarize from their friends who had good English. Students who resorted to plagiarism were found to be weak in paraphrasing English sentences, which led them into "cutting and pasting" whole sentences or simply altering a few keywords from the plagiarized text. They also did not know how to reference sources correctly (Lahur, 2004).

In Marshall and Garry (2005), a greater prevalence of Internet plagiarism in completing assignments was detected among students from non-English speaking backgrounds (NESB) than those from English-speaking ones (ESB). The NESB group did not have a clear understanding of what constitutes plagiarism, and showed less respect for the intellectual property of material on the web. In agreement with Marshall and Garry (2005) on the issue of proficiency, Maxwell, Curtis and Vardanega (2008) observed that Asian students not fluent in English had technical problems in writing, especially in terms of summarizing, synthesizing and rephrasing the ideas of others in various ways or styles. Essentially, the difficulty was caused by their inability to express ideas in English.

\section{Subject-Matter Competency and Internet Plagiarism}

The assumption that good students plagiarize less than weak students, and the connection between subject-matter competency and plagiarism have received little treatment in the research literature. Only two studies have looked into this, and discovered significant differences in the plagiarism rates of students with low and high grades. Lidija et al. (2005) found that medical students with better grades plagiarized less compared to those with lower grades. Selwyn's (2008) findings supported this pattern, revealing that students with good Alevel results did less verbatim copying of information than their less able peers. Although scant, the evidence suggests that subject-matter competency and academic achievement may also influence students' tendency to plagiarize. 


\section{Statement of the Problem}

At the selected secondary school in Kuala Lumpur where the study was conducted, students are required to produce a good number of written projects, reports and portfolios for their school subjects. The written assignments are a requirement for the recently implemented School Based Assessment (SBA) for subjects like Science, Physics, Biology, Chemistry, History and Geography. To complete the assignments, students must refer to and synthesize various sources of information including the Internet. Since the SBA was introduced, teachers frequently detected plagiarized work by students of the school who simply copied and pasted information from websites without rephrasing or proper citation. Although the marks students obtain from the assignments do not affect their final grades, the practice creates an unhealthy academic culture and suggests that Internet plagiarism might be an epidemic at the school. However, the extent to which it might be an epidemic is not known because no effort has been taken by the school and teachers to explore this phenomenon among students.

There is a large amount of existing research data on Internet plagiarism (Ma et al., 2007; Scanlon \& Neumann, 2002; Selwyn, 2008; Sisti, 2007), but most of the work was done in nonMalaysian contexts. In addition, a majority of the studies concentrated on college and university students. Studies that involved middle and high school students were few and were conducted primarily in the United States. As such, the findings of these studies are limited in terms of their applicability to understand and explain Internet plagiarism in the Malaysian context. Simultaneously, after having thoroughly checked through online databases (including the IIUM online database), Google scholar and ERIC, the researchers were able to locate only two Malaysian studies (Rosman et. al., 2012; Yusof \& Masrom, 2011) which had surveyed university students' engagement in Internet plagiarism. Alternatively, the researchers could not retrieve any study conducted among secondary school students in Malaysia.

Besides gender, the achievement factor has also been studied extensively in terms of its influence on and relationship with plagiarism tendencies. Several studies indicated that high achievers plagiarize less compared to low achievers (Lidija et al., 2005; Neil Selwyn, 2008). Understandably, higher academic ability comes with a lesser plagiarism tendency. An apparent gap in this area is the lack of studies on student plagiarism in specific school subjects, i.e., Science, Chemistry, Physics or Biology. Thus, research in this area is warranted, especially one that looks into the relationship between student achievement and Internet plagiarism, as well as gender differences in the issue.

One would also ask if English language competency has an influence on Internet plagiarism as this question has prompted some research into it. Since English is used quite a lot in Malaysian schools and universities as the language of teaching and learning, students who are incompetent in it would encounter some difficulty in getting their written assignments done. Many perhaps take the easy way out by copying and pasting information verbatim from the Internet and turning it into their term papers (Lahur, 2004; Marshall \& Garry, 2005; Maxwell, Curtis, \& Vardanega, 2008). How prevalent this practice is among secondary school students is yet to be known. 


\section{Research Objectives and Questions}

Hence, this study was conducted with the purpose of exploring and understanding the prevalence (i.e., the percentage of students from the total population that engaged in Internet plagiarism) and extent (i.e., the amount of material plagiarized) of Internet plagiarism among upper secondary students taking Chemistry as a subject. The study, which took place at a selected public school in Kuala Lumpur, also sought to establish whether the construct is associated with gender, Chemistry achievement and English proficiency. With these aims in mind, the following three research questions were posed:

1. What is the extent and prevalence of Internet plagiarism among the selected school's Form Five students in the given Chemistry assignment?

2. Is there a statistically significant gender difference in the extent of Internet plagiarism in the given Chemistry assignment?

3. Are students' achievements in Chemistry and English correlates of Internet plagiarism?

\section{METHODS}

\section{Research Design}

The research was a quantitative case study that examined the phenomenon and extent of Internet plagiarism among the entire population of Form Five students taking the Chemistry subject at a selected secondary school in Kuala Lumpur. The design was categorized as a case study because the entire population was examined, and quantitative because the data were analyzed using the method of quantified document analysis. In this method, students' written assignments on Acid Rain were the documents analyzed to discover the prevalence and extent of Internet plagiarism.

\section{Participants}

The case study involved the entire population of Form Five Chemistry students at the selected school $(\mathrm{N}=87)$. The school is one of the entities included in the Smart School Project under the Ministry of Education Malaysia. As such, the students have a lot of access to computer and Internet facilities which were provided to assist in the learning process. At the time of data collection, the total number of students taking Chemistry as an elective subject was 87, of whom 36 were boys and 51 were girls (Table 1) promote the development of English language learning.

Table 1

Breakdown of Study Participants by Gender

\begin{tabular}{ccc}
\hline Gender & N & Percentage \\
\hline Male & 36 & $41 \%$ \\
Female & 51 & $59 \%$ \\
\hline Total & 87 & $100 \%$ \\
\hline
\end{tabular}


All of them were between 16 and 17 years of age and were taking Chemistry as an elective subject in the Science stream. The subject was taught in English and all assignments were to be submitted in English.

\section{Materials for Document Analysis}

The students were required to write a two-page double-spaced essay of between 500 and 550 words to show their understanding of Acid Rain, a small topic in the Chemistry syllabus. In the essay, they must explain the following: (1) What is acid rain? (2) How acid rain is formed; and (3) The effects of acid rain on life forms and the environment. The essay must be written in English as it was the language of instruction for the subject at school. The essays were the documents that provided data for the analysis.

\section{Instruments}

A coding form was created to guide the scoring of the essays on Acid Rain. The form explained how to award marks to the plagiarized content. For every plagiarized sentence, an award of 1 mark would be given. For every half sentence plagiarized, a 1/2 mark would be awarded. The essays were also run through Turnitin, the plagiarism detection software.

\section{Data Collection}

After one week of traditional teacher instruction on acid rain, students were instructed to write an essay on the topic for their Chemistry assignment. They were given two weeks to write the two-page essay on the meaning of acid rain, how it is formed, and its effects on living things and the environment. Students were told that they could take and synthesize information from multiple sources including the Internet, books, magazines, and encyclopedias. Before writing the essay, the participating Chemistry teacher reminded them to read through all information thoroughly to understand it, rephrase the ideas, and cite the sources properly. The students were told that the essay would not affect their Chemistry marks. After two weeks, students submitted their essays in the form of softcopy (saved on a CD or pen drive) or through e-mail.

\section{Data Analysis}

This research employed quantified document analysis which used individual sentences as the units of analysis. Students' essays on acid rain were scrutinized closely to find sentences that matched with existing Internet sources. The search for matching sentences or phrases was done manually using Google. In addition, the study also relied on Turnitin to generate the similarity indexes on the essays. The indexes generated by Turnitin were compared against those produced manually by the researchers.

\section{Determining the Extent of Internet Plagiarism}

The extent (or amount) of Internet plagiarism refers to the percentage of plagiarized text over the total number of sentences incorporated in individual students' essays. Each plagiarized sentence was given a score of 1 , while a plagiarized phrase was given a $1 / 2$ score. The formula used to determine the amount of plagiarized text was as follows:

$$
\text { The whole number of sentences in the essay } \times 100
$$


How the essays were coded and scored is shown in Figures 1 and 2:

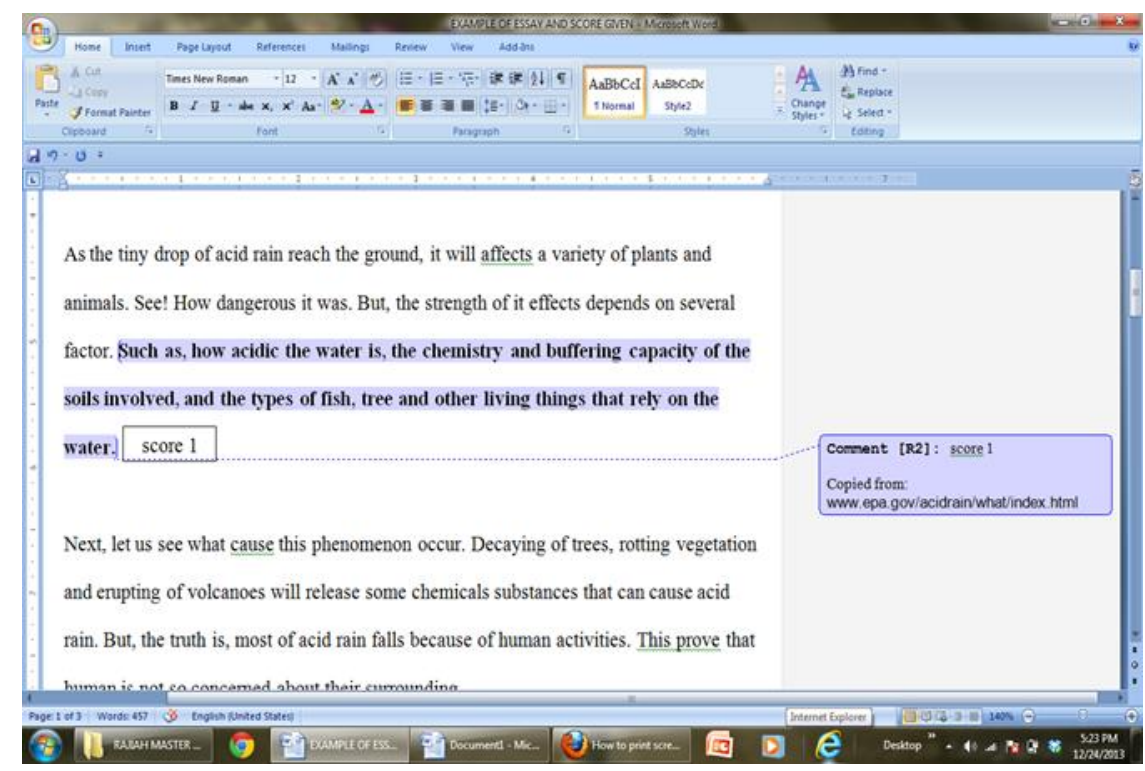

Figure 1: How a Score of 1 was Awarded

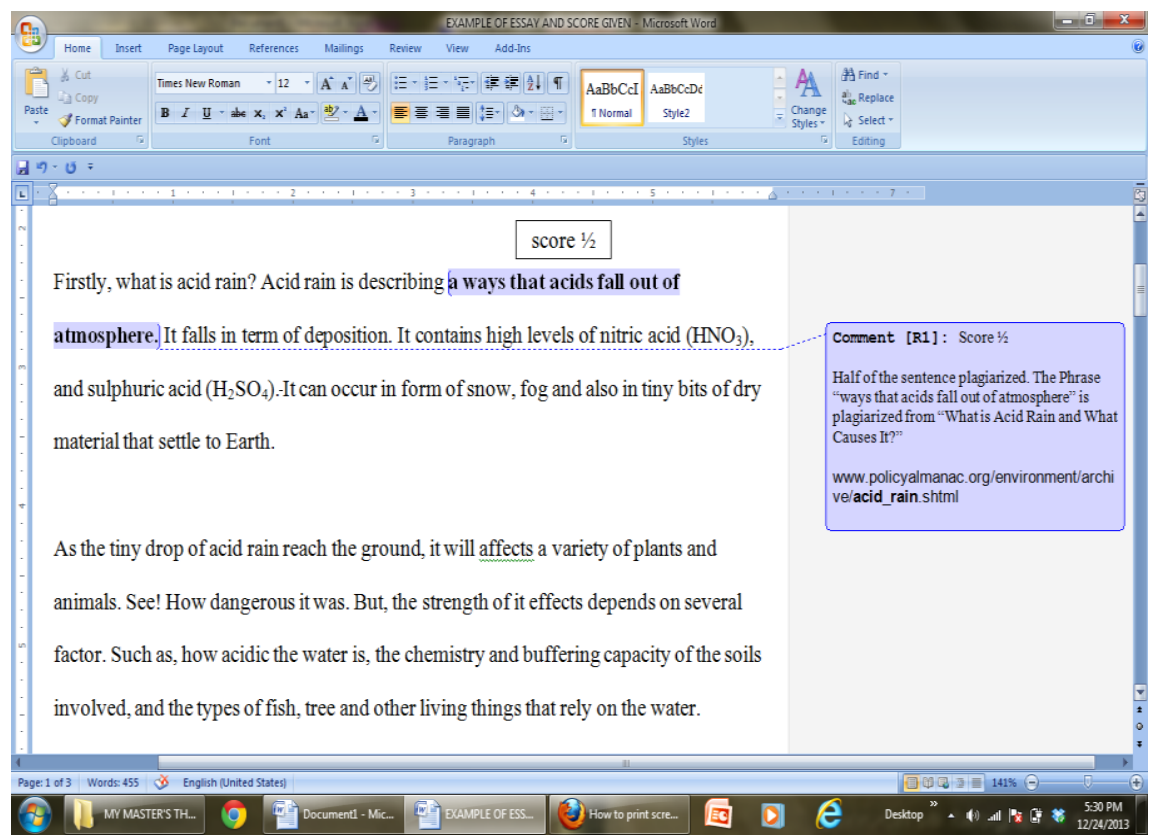

Figure 2: How a Score of Half was Awarded

The total score obtained for each individual essay constituted the amount of plagiarized text, hence the respective student's extent of Internet plagiarism. The essays were also run through Turnitin to generate similarity indexes. These descriptive analyses addressed the first part of Research Question 1, i.e. "What is the extent and prevalence of Internet plagiarism among the selected school's Form Five students in the given Chemistry assignment? 


\section{Determining the Prevalence of Internet Plagiarism}

"Prevalence" refers to how widespread plagiarism is among the participants, indicated by the number of students who plagiarized in the Acid Rain assignment divided by the total population of the school's Form Five students who were taking Chemistry at the time of data collection. The formula used to determine the rate was as follows:

The number of Form Five Chemistry students who plagiarized The population of Chemistry students (87 students)

X 100

Descriptive statistics were used to find the rate of Internet plagiarism. The analysis addressed the second part of Research Question One, "What is the extent and prevalence of Internet plagiarism among the selected school's Form Five students in the given Chemistry assignment?"

\section{Gender Differences in Extent of Internet Plagiarism}

The study ran an independent samples $t$-test to see if there were gender differences, if any, on the amount of plagiarized text present in the students' Acid Rain essays. The t-test analysis addressed the second research question, "Is there a statistically significant gender difference in the amount of Internet plagiarism in the given Chemistry assignment?"

\section{Relationships between Achievements in Chemistry and English and Internet Plagiarism}

Two Pearson Product-Moment correlation analyses were run to assess the relationships between the extent of Internet plagiarism and two sets of scores indicating students' Chemistry achievement and English proficiency. Chemistry achievement and English proficiency were represented by the students' Chemistry and English marks obtained in the school's mid-term examination. The strength of the correlations was interpreted using Taylor's (1990) guidelines (Table 2).

Table 2

Taylor's (1990) Guidelines for Interpreting Correlation Strength

\begin{tabular}{cc}
\hline$r$ value & Correlation Strength \\
\hline 0.35 or less & Low/Weak \\
$0.36-0.67$ & Modest/Moderate \\
$0.68-0.89$ & High/Strong \\
$0.90-0.99$ & Very High/Very Strong \\
1.00 & Perfect \\
\hline
\end{tabular}

The analyses addressed the final research question, "Are students' achievements in Chemistry and English correlates of Internet plagiarism?"

\section{Determination of Cut-off Points for Internet Plagiarism}

A cut-off point is the point at which an essay can be considered as plagiarized. The cut-off point for this study was set at $23 \%$ similarity index to be consistent with that used by Turnitin. This study adapted the cut-off points used in Batane (2010) and Walker (2010) to divide plagiarism into four categories. Table 3 below summarizes the plagiarism categories used in the study. 
Table 3

Plagiarism Categories Modified from Batane (2010) and Walker (2010)

\begin{tabular}{ll}
\hline $\begin{array}{c}\text { Percentage of plagiarized text } \\
\text { (Amount of plagiarism) }\end{array}$ & Category \\
\hline $23 \%$ or less & No plagiarism \\
$24-34 \%$ & Low scale plagiarism \\
$35-55 \%$ & Medium scale plagiarism \\
More than $55 \%$ & High scale plagiarism \\
\hline
\end{tabular}

It After being coded for amount of Internet plagiarism, the essays were classified into four categories: (i) $23 \%$ or less was considered as no plagiarism; (ii) $24 \%$ to $34 \%$ as low scale plagiarism; (iii) $35 \%$ to $55 \%$ as medium scale plagiarism; and (iv) more than 55\% as high scale plagiarism (adapted from Batane, 2010; Walker, 2010).

\section{Reliability}

Two inter-rater reliability measures were estimated for the coding on the extent (amount) of Internet plagiarism using two sets of correlation analysis. The purpose of the correlation analysis was to determine the association between the coding done by the researchers and that by another coder, as well as with the Turnitin similarity indexes. This would, therefore, establish the consistency or reliability of the measure. To meet this objective, a second rater was appointed to code the amount of plagiarized text. Thirty essays were used, 15 written by boys and 15 by girls. The rater was an experienced Science teacher with good computer and Internet search skills. She was personally trained by the researcher to code the essays and award plagiarism scores accordingly. The set of scores given by the second rater was entered into SPSS as "Second Coder Scores".

\section{RESULTS}

\section{Extent and Prevalence of Internet Plagiarism}

To reiterate, "extent" in this case study refers to the amount of text or information in the students' Acid Rain essays that was plagiarized from Internet sources. The amount was determined based on researcher-coded scores and Turnitin similarity indexes. Table 4 tabulates the scores and Turnitin indexes for all 87 students whose essays were examined in the study. 
Table 4

Tabulation of Students' Internet Plagiarism Scores by Researcher Coding and Turnitin Index $(\mathrm{N}=87)$

\begin{tabular}{cccc|cccc}
\hline \multirow{2}{*}{ Students } & \multirow{2}{*}{ Gender } & \multicolumn{2}{c|}{ Plagiarism Scores } & \multicolumn{2}{l}{ Students } & Gender & \multicolumn{2}{c}{ Plagiarism Scores } \\
\cline { 3 - 5 } & & Researcher & Turnitin & & Researcher & Turnitin \\
\hline P_06 & M & 100 & 100 & P_16 & F & 100 & 96 \\
P_69 & M & 100 & 100 & P_21 & F & 100 & 96 \\
P_54 & F & 100 & 100 & P_26 & F & 100 & 96 \\
P_38 & F & 100 & 100 & P_01 & M & 100 & 96 \\
P_51 & F & 100 & 100 & P_35 & F & 100 & 96 \\
P_61 & M & 100 & 99 & P_44 & F & 100 & 96 \\
P_67 & M & 100 & 99 & P_30 & M & 100 & 96 \\
P_87 & M & 100 & 99 & P_49 & F & 100 & 96 \\
P_68 & M & 100 & 99 & P_62 & M & 100 & 96 \\
P_83 & F & 100 & 99 & P_81 & F & 100 & 96 \\
P_70 & M & 100 & 98 & P_63 & M & 100 & 94 \\
P_72 & M & 100 & 98 & P_82 & F & 100 & 94 \\
P_86 & M & 100 & 98 & P_71 & M & 100 & 94 \\
P_59 & F & 100 & 98 & P_11 & M & 100 & 93 \\
P_31 & M & 100 & 98 & P_18 & F & 100 & 92 \\
P_09 & M & 100 & 98 & P_23 & F & 100 & 92 \\
P_42 & F & 100 & 98 & P_80 & F & 100 & 91 \\
P_55 & F & 100 & 97 & P_20 & F & 100 & 90 \\
P_58 & F & 100 & 97 & P_22 & F & 100 & 90 \\
P_77 & F & 100 & 97 & P_78 & F & 100 & 89 \\
P_36 & F & 100 & 97 & P_56 & F & 100 & 86 \\
P_45 & F & 100 & 97 & P_79 & F & 100 & 85 \\
P_74 & M & 100 & 97 & P_57 & F & 100 & 82 \\
P_08 & M & 100 & 79 & P_32 & M & 88 & 94 \\
P_02 & M & 99 & 97 & P_04 & M & 88 & 87 \\
P_73 & M & 99 & 83 & P_64 & M & 86 & 81 \\
P_17 & F & 98 & 93 & P_27 & F & 84 & 93 \\
P_85 & F & 98 & 91 & P_28 & M & 84 & 90 \\
\hline & & & & & & & \\
\hline
\end{tabular}


Table 4 (continued)

\begin{tabular}{cccc|cccc}
\hline \multirow{2}{*}{ Students } & \multirow{2}{*}{ Gender } & \multicolumn{2}{c}{ Plagiarism Scores } & \multicolumn{3}{c}{ Students } & \multicolumn{2}{c}{ Pender } & Resiarism Scores \\
\cline { 3 - 5 } & & Researcher & Turnitin & & & RerTurnitin \\
\hline P_52 & F & 98 & 89 & P_53 & F & 83 & 94 \\
P_76 & F & 97 & 96 & P_37 & F & 83 & 87 \\
P_41 & F & 97 & 95 & P_14 & F & 83 & 86 \\
P_48 & F & 97 & 92 & P_66 & M & 79 & 87 \\
P_47 & F & 96 & 96 & P_25 & F & 74 & 88 \\
P_50 & F & 96 & 92 & P_39 & F & 73 & 82 \\
P_05 & M & 93 & 97 & P_29 & M & 71 & 90 \\
P_84 & F & 93 & 92 & P_43 & F & 70 & 83 \\
P_19 & F & 92 & 93 & P_46 & F & 68 & 70 \\
P_75 & F & 92 & 89 & P_60 & F & 68 & 85 \\
P_03 & M & 92 & 95 & P_40 & F & 54 & 56 \\
P_33 & M & 91 & 91 & P_10 & M & 47 & 48 \\
P_13 & M & 91 & 98 & P_15 & F & 43 & 39 \\
P_65 & M & 90 & 91 & P_34 & M & 34 & 52 \\
P_12 & F & 88 & 96 & P_24 & F & 1 & 6 \\
P_07 & M & 88 & 95 & & & & \\
\hline
\end{tabular}

The results show a huge majority of the students were involved in high scale plagiarism where $94 \%(n=82)$ had a plagiarism score of more than 55\%. Based on the match between Turnitin and researcher-coded scores, five $(6 \%)$ students completely lifted out their essays from the Internet. Four students (5\%) plagiarized at a medium scale, i.e. between 35 and 55\%. Only one student was free from plagiarism. The results are summarized in Table 5.

Table 5

Extent of Internet Plagiarism $(\mathrm{N}=87)$

\begin{tabular}{lcc}
\hline \multicolumn{1}{c}{ Category } & $\mathrm{N}$ & $\%$ \\
\hline No plagiarism & 1 & $1 \%$ \\
Low scale plagiarism & -- & -- \\
Medium scale plagiarism & 4 & $5 \%$ \\
High scale plagiarism & 82 & $94 \%$ \\
\hline \multicolumn{1}{c}{ Total } & 87 & $100 \%$ \\
\hline
\end{tabular}

The results in Table 5 summarize the prevalence of Internet plagiarism among the students. Only one student did not plagiarize at all, while the remaining $86(99 \%)$ plagiarized in varying degrees. Therefore, the prevalence or rate of plagiarism among the population under study was $99 \%(\mathrm{n}=86$ ), which was extremely high. In other words, almost everyone plagiarized to get their assignments done. 


\section{Reliability of the Internet Plagiarism Measures}

Inter-rater reliability was estimated for the measures of Internet plagiarism. Correlation analyses were run on the researcher-coded scores and Turnitin similarity indexes, as well as between two sets of 15 Acid Rain essays coded by the researchers and one independent rater. The correlation between the scores and Turnitin indexes is a very strong one and statistically significant, $\mathrm{r}(87)=.905, \mathrm{p}=.001$. Similarly, the scores generated by the independent raters are strongly and significantly correlated, $\mathrm{r}(30)=.922, \mathrm{p}=.001$. All measures are positively and significantly correlated, indicating high consistency in the scoring and coding of plagiarism amount present in the students' Acid Rain essays.

\section{Gender Differences in Internet Plagiarism}

Table 6 shows the plagiarism mean scores of boys $(n=36)$ and girls $(n=51)$ by researcher coding and Turnitin. Descriptively, boys plagiarized slightly more than girls. Both their researcher-coded and Turnitin mean scores were higher than those of girls by 0.93 and 2.96 points, respectively.

Table 6

A Comparison between Boys and Girls in Plagiarism Amount $(\mathrm{N}=87)$

\begin{tabular}{llllc}
\hline \multicolumn{1}{c}{ Plagiarism Amount } & Gender & $\mathrm{N}$ & Mean & SD \\
\hline Researcher-Coded & Female & 51 & 90.94 & 18.26 \\
& Male & 36 & 91.87 & 14.59 \\
Turnitin & Female & 51 & 88.82 & 15.88 \\
& Male & 36 & 91.78 & 11.58 \\
\hline
\end{tabular}

The differences, however, were too slight to account for any statistical significance. This was attested by the independent samples $t$-test results showing no significant difference between boys' $(\mathrm{M}=91.87 ; \mathrm{SD}=14.59)$ and girls' $(\mathrm{M}=90.94 ; \mathrm{SD}=18.26)$ researcher-coded scores; $\mathrm{t}(85)=-.254, \mathrm{p}=.800$. The same non-significant difference was found for the Turnitin mean scores for boys $(\mathrm{M}=91.78 ; \mathrm{SD}=11.58)$ and girls $(\mathrm{M}=88.82 ; \mathrm{SD}=15.88) ; \mathrm{t}(85)=-.952$, $\mathrm{p}=.334$.

\section{Internet Plagiarism and Student Achievements in English and Chemistry}

Is the extent of Internet plagiarism (represented by the researcher-coded scores and Turnitin indexes) associated with student achievements in Chemistry and English? The study ran two sets of bivariate analysis to answer this question. The results are summarized in Table 7. 
Table 7

Relationship between Measures of Plagiarism Extent and Achievements in Chemistry and English $(\mathrm{N}=87)$

\begin{tabular}{ccllc}
\hline Association & $\begin{array}{c}\text { Coefficient } \\
(r)\end{array}$ & $p$ value & Direction & $\begin{array}{c}\text { Strength of } \\
\text { Association }\end{array}$ \\
\hline CA and RCS & -.298 & $.005^{*}$ & negative & weak \\
CA and TURN & -.211 & $.051^{* *}$ & negative & weak \\
EA and RCS & -.300 & $.005^{*}$ & negative & weak \\
EA and TURN & -.310 & $.004^{*}$ & negative & weak
\end{tabular}

Note $: \mathrm{CA}=$ Chemistry Achievement; EA = English Achievement; RCS = Researcher-Coded Scores; TURN = Turnitin Indexes; *statistically significant at $p<0.05$; **not statistically significant at $p>0.05$

Plagiarism extent, represented by the researcher-coded scores, is significantly and negatively associated with both measures of student achievement. The association is, however, a weak one (Taylor, 1990). The same weak correlations are observed for Turnitin scores and students' achievements in Chemistry and English, although the relationship is significant for the former but insignificant for the latter. All relationships are inverse, which means that the lower the achievement, the higher the plagiarism extent. In other words, the more competent the student is in English and Chemistry, the lesser the plagiarism extent. A descriptive analysis shows that the students' average scores are quite low, i.e. $63.74 \%$ for English and $57 \%$ for Chemistry.

\section{DISCUSSION}

The study found that Internet plagiarism among upper secondary students in the selected Malaysian public school was widespread (i.e. almost $99 \%$ as everyone but one female student plagiarized) and extremely high at an average amount of $90 \%$ for Turnitin and $91.3 \%$ for researcher-coded scores. The finding agrees with Lidija et al. (2005) who found only a small percentage of students to be free from Internet plagiarism, and supports the results of others (e.g., Ma et. al, 2007; Selwyn, 2008; Sisti, 2007) that discovered the practice to be epidemic among students. In fact, the younger users, namely teenagers, have better understanding and skills on how to find information online (Van Deursen \& Van Dijk, 2011).

Gender wise, both boys and girls plagiarized at about the same extent, and the slight difference between them did not account for any statistical significance. Most were involved in high-scale plagiarism, and appeared to have lifted their essays completely off the Internet. The pattern is the same as that observed by Lidija et al. (2005) and Walker (2010). In an earlier work, Rajiah (2012) had explored this phenomenon qualitatively among younger students in the same school and found similar results. Internet plagiarism was epidemic. Being part of the Ministry's Smart Project, the school is equipped with good Internet infrastructure and Internet facilities, and naturally its students would be well-exposed to a digitalized teaching and learning culture (Ya'acob, Nor, \& Azman, 2005). Within the school parameters, access to online materials is equal to all students regardless of gender. Furthermore, in the Malaysian context, male and female students are highly exposed to computers and the Internet, and gender disparity where ICT is concerned is quickly disappearing. Therefore, all the students in the case study had an equal likelihood of plagiarizing given their equal access to the Internet and their comparable computer skills and Internet literacy. 
A more interesting question to ask would be, "Why did they plagiarize?" As explained by Jensen et al. (2002), young students at school tend to regard cheating as an acceptable way of getting their assignments done. As high school is academically less serious than college, most do not look at Internet plagiarism as a serious problem. Students in this age group also lack the maturity to evaluate the act as morally wrong.

A favourite website for plagiarism among the students was Wikipedia as the website is a good place to start one's reading about a topic. There is a likelihood that the students did so due to their lack of ability in English. The essay assignment did demand good writing skills, and the students might have found it difficult considering their rather low English proficiency measure $(63.7 \%)$. The essay also required the ability to synthesize information on Acid Rain, and given their low competency in Chemistry, lifting content off available websites might have been the easy way out. The study could not completely ascertain whether students' lack of ability in English and Chemistry was the actual reason for their plagiarism act as measures of the two subjects turned out to be weak correlates of plagiarism. Other factors might have been at play. As low proficiencies in English and Chemistry were weak correlates of Internet plagiarism, three factors related to the school culture might have been instrumental: (i) students' limited knowledge and awareness of plagiarism; (ii) plagiarism accepted as a "normal" practice; and (iii) too easy an access to the Internet (Rajiah, 2012). These are areas that future studies can look into.

\section{RECOMMENDATIONS}

Based on the findings, the study makes the following recommendations for schools and the authorities concerned to curb the spread of Internet plagiarism among students: (i) Assignments should be authentic in nature and cannot simply be completed by copying and pasting information from Internet sources; (ii) students must be explicitly taught how to write coherently, how to summarize, synthesize and paraphrase ideas, and how to cite sources properly in their written works; (iii) students should be educated on the meaning and forms of plagiarism and Internet plagiarism; and finally (iv) schools should teach students how to write well and think critically and independently. Perhaps the Ministry of Education and curriculum developers can build these skills into the curriculum as an effort to curb Internet plagiarism. 


\section{REFERENCES}

Al-Rafee, S., \& Cronan, T. P. (2006). Digital piracy: Factors that influence attitude toward behavior. Journal of Business Ethics, 63(3), 237-259.

Austin, M. J., \& Brown, L. D. (1999). Internet plagiarism: Developing strategies to curb student academic dishonesty. Internet and Higher Education, 2, 21-34.

Aziz, N. E. A., Sahrani, R., Zaini, M. K., \& Kamaruddin, H. D. (2013). Information searching skills among Malaysian youth: The case of National Service Training Programme (NSTP) trainees, Selangor Malaysia.The Macrotheme Review, 2(1), 8-18

Batane, T. (2010). Turning to Turnitin to fight plagiarism among university students. Educational Technology \& Society, 13(2), 1-12.

Breen, L., \& Maassen, M. (2005). Reducing the incidence of plagiarism in an undergraduate course: The role of education. Issues in Educational Research, 15(1), 1-16.

Bretag, T., \& Mahmud, S. (2009). A model for determining student plagiarism: Electronic detection and academic judgement. Journal of University Teaching \& Learning Practice, 6(1), 6.

Chan, F.-M. (2002). ICT in Malaysian schools: Policy and strategies. In Seminar/Workshop on the Promotion of ICT in Education to Narrow the Digital Divide (pp. 15-22).

Combating Plagiarism. (n.d.). CQ Researcher by CQ Press. Retrieved from http://library.cqpress.com/cqresearcher/cqresrre2003091900

Conradson, S., \& Hernández-Ramos, P. (2004). Computers, the internet, and cheating among secondary school students: Some implications for educators. Practical Assessment, Research and Evaluation, 9(9).

Culwin, F., \& Lancaster, T. (2000). A review of electronic services for plagiarism detection in student submissions. In LTSN-ICS 1st Annual Conference (pp. 23-25).

Daly, C., \& Horgan, J. M. (2007). Profiling the plagiarists: An examination of the factors that lead students to cheat. Journal of Educational Computing Research, 36(1), 39-50.

Denning, P. J. (1995). Plagiarism in the Web. Communications of the ACM, 38(12), 29.

Evans, R. (2006). Evaluating an electronic plagiarism detection service: The importance of trust and the difficulty of proving students don't cheat. Active Learning in Higher Education, 7(1), 87-99.

Hargittai, E., \& Shafer, S. (2006). Differences in actual and perceived online skills: The role of gender*. Social Science Quarterly, 87(2), 432-448.

Rajiah, H. (2012). Awareness of Internet Plagiarism among the Secondary School Students in Gombak, Selangor, Malaysia. IAMURE. The International Journal of Social Sciences, 2(1), 205-216 
Higgins, G. E., Wolfe, S. E., \& Marcum, C. D. (2008). Digital piracy: An examination of three measurements of self-control. Deviant Behavior, 29(5), 440-460.

Howard, R. M. (2007). Understanding "Internet plagiarism." Computers and Composition, 24(1), 3-15.

Ismail, S. (2008). ICT and school linkages. In ICT Conference 2008. Retrieved from http://sdmuhcc.net/jogjabelajar/aridata_web/moe/MALAYSIA\%20ICT\%20and\%20S chool\%20Linkages.pdf

Ison, D. C. (2012). Plagiarism among dissertations: Prevalence at online institutions. Journal of Academic Ethics, 10(3), 227-236.

Jensen, L. A., Arnett, J. J., Feldman, S. S., \& Cauffman, E. (2002). It's wrong, but everybody does it: Academic dishonesty among high school and college students. Contemporary Educational Psychology, 27(2), 209-228.

Lahur, A. M. (2004). Plagiarism among Asian students at an Australian university offshore campus: Is it a cultural issue? A pilot study. In Proceedings of the HERDSA Conference. Retrieved from http://www.herdsa.org.au/wpcontent/uploads/conference /2004/PDF/ A033-jt.pdf

Lass, P., Bandurski, T., Swietlik, D., Tomczak, H., \& Wengler, L. (2006). Student's plagiarism-a challenge for paramedic educators. Nuclear Medicine Review, 9(1), 89.

Leng, G. S., Lada, S., Muhammad, M. Z., Ibrahim, A., \& Amboala, T. (2011). An exploration of Social Networking Sites (SNS) adoption in Malaysia using technology acceptance model (TAM), Theory of Planned Behavior (TPB) and intrinsic motivation. Journal of Internet Banking and Commerce, 16(2), 1-27.

Lidija, Vedran, Tamara, Josip, \& Mladen, S. (2005). Prevalence of plagiarism among medical students. Croat Med J, 46(1), 126-131.

Klausman, J. (1999). Teaching about plagiarism in the age of the Internet. Teaching English in the Two Year College, 27(2), 209-212.

Ma, H., Lu, E. Y., Turner, S., \& Wan, G. (2007). An empirical investigation of digital cheating and plagiarism among middle school students. American Secondary Education, 69-82.

Maneggia, D. (2007). Plagiarism in the 21st Century. Retrieved from http://www.tne. uconn. edu/nera07/maneggia\%20plagiarism\%20nera\%202007\%20_2_.pdf

Marshall, S., \& Garry, M. (2005). How well do students really understand plagiarism. In Proceedings of the 22nd annual conference of the Australasian Society for Computers in Learning in Tertiary Education (ASCILITE) (pp. 457-467).

Maxwell, A., Curtis, G. J., \& Vardanega, L. (2008). Does culture influence understanding and perceived seriousness of plagiarism? International Journal for Educational Integrity, $4(2)$. 
Mobile, N. (2009). How teens use media: A Nielsen report on the myths and realities of teen media trends. Retrieved from http://www.nmprevention.org/Project_Docs/Nielsen_ HowTeensUseMedia_June2009.pdf

Olcott, M. (2001). Ancient and modern notions of plagiarism: A study of concepts of intellectual property in classical Greece. Journal of the Copyright Society of the U.S.A., 49, 1047.

Price, J., \& Price, R. (2005). Finding the true incidence rate of plagiarism. International Education Journal, 6(4), 421-9.

Rosman, A. S., Hassan, A. M., Suratman, A. S., Ripin, M. N., \& Marni, N. (2012). Persepsi pelajar Universiti Teknologi Malaysia (UTM) terhadap plagiarisme. Jurnal Teknologi, 48(1), 1-14.

Sam, H. K., Othman, A. E. A., \& Nordin, Z. S. (2005). Computer self-efficacy, computer anxiety, and attitudes toward the Internet: A study among undergraduates in Unimas. Educational Technology \& Society, 8(4), 205-219.

Scanlon, P. M., \& Neumann, D. R. (2002). Internet plagiarism among college students. Journal of College Student Development, 43(3), 374-385.

Selwyn, N. (2008). "Not necessarily a bad thing...": A study of online plagiarism amongst undergraduate students. Assessment \& Evaluation in Higher Education, 33(5), 465479.

Sisti, D. A. (2007a). How do high school students justify internet plagiarism? Ethics \& Behavior, 17(3), 215-231.

Taylor, R. (1990). Interpretation of the correlation coefficient: A basic review. Journal of Diagnostic Medical Sonography, 6(1), 35-39.

Teck, S. H., \& Lai, Y. L. (2011). An empirical analysis of Malaysian pre-university students' ICT competency gender differences. International Journal of Network and Mobile Technologies, 2(1).

University of Cambridge (2011). HPS : Plagiarism guidelines Retrieved from http://www. hps.cam.ac.uk/students/plagiarism.html

Van Deursen, A., \& Van Dijk, J. (2011). Internet skills and the digital divide. New Media \& Society, 13(6), 893-911.

Walker, J. (2010). Measuring plagiarism: Researching what students do, not what they say they do. Studies in Higher Education, 35(1), 41-59.

Wee, S. H. (1999). Internet use amongst secondary school students in Kuala Lumpur, Malaysia. Malaysian Journal of Library \& Information Science, 4(2), 1-20. 
Williams, K. M., Nathanson, C., \& Paulhus, D. L. (2010). Identifying and profiling scholastic cheaters: Their personality, cognitive ability, and motivation. Journal of Experimental Psychology: Applied, 16(3), 293.

Ya'acob, A., Nor, N., \& Azman, H. (2005). Implementation of the Malaysian Smart School: An investigation of teaching-learning practices and teacher-student readiness. Internet Journal of e-Language Learning \& Teaching, 2(2), 16-25.

Yusof, D. S., \& Masrom, U. K. (2011). Malaysian students' understanding of plagiarism. Malay, 35, 72-9. 